AKÜ FEMÜBiD 18 (2018) 017204 (397- 402)

AKU J. Sci. Eng. 18 (2018) 017204 (397-402)

DOI: $10.5578 / \mathrm{fmbd} .66811$

\title{
Performance Analysis of GBAS Vertical Protection Levels for Civil Aircraft Precision Approach and Landing using GPS and GLONASS
}

\author{
Irfan Sayim \\ Gebze Teknik Üniversitesi, Mühendislik Fakültesi, Harita Mühendisliği Bölümü, Gebze - Kocaeli. \\ i.sayim@gty.edu.tr
}

Keywords

Satellite Outages,

Availability, VPL/VAL,

GBAS Integrity,

GAD, AAD,

GPS, GLONASS

\begin{abstract}
In this paper, an analysis has been performed to quantify and compare the Vertical Protection Levels (VPLS) performances using GPS (Global Positioning System) and GLONASS (GLObal NAvigation Satellite System - GLObalnaya NAvigatsionnaya Sputnikovaya Sistema) satellite navigation systems for the largest Turkish Airport (Istanbul Ataturk Airport - IST). The VPLs are position error bounds computed at aircraft with ensured high navigation performances for initiation of intendent precision aircraft approach and landing in the Ground Based Augmentation System (GBAS). The GBAS, therefore, is an advanced navigation system and designed to provide civil aircraft user with high navigation performances. All defined algorithms in GBAS are built entirely on the GPS positioning solutions. In this study, an alternative constellation of global satellite navigation system GLONASS is considered and its performances are quantified for potential usability in future. In this respect, IST is selected as an implementation site in analysis. Two approaches have been proposed in the quantification of system availability for the given site; a) full constellation with increased elevation mask, b) two satellite outages as a worst-case scenario in the quantification of system availability. Investigations have shown that the GPS could provide superior performance over GLONASS in compliance with the GBAS availability requirements (i.e., exhibits high performance). However, the outcomes are also promising for the prescribed GBAS VPL performance using an alternative constellation (GLONASS) for supporting a precision approach and landing of an aircraft at the IST.
\end{abstract}

\section{Sivil Havacılık Uçak Yaklaşma ve İnişinde GPS ve GLONASS Kullanılarak Bulunan GBAS Düşey Koruma Seviyelerinin Performans Analizi}

\section{Anahtar kelimeler Uydu Devredışılık, Uygunluk, VPL/VAL, GBAS Güvenilirliği, \\ GAD, AAD, \\ GPS, GLONASS}

\begin{abstract}
Özet
Bu çalışmada, Turkiye'nin en büyük havaalanı (İstanbul Atatürk Havaalanı - IST) için GPS (Global Positioning System) ve GLONASS (GLObal NAvigation Satellite System - GLObalnaya NAvigatsionnaya Sputnikovaya Sistema) uydu navigasyon sistemleri kullanılarak düşey koruma seviyeleri'nin (VPL) performansları hesaplanmış ve karşılaştırılmıştır. VPL'ler, konum sınırlama değerleri olup yüksek güvenilirlikle uçak'ta hesaplanır ve GBAS'in (Yer Temelli Genişleme Sistemi) uçak hassas yaklaşma ve inişinde kullanılır. Bundan dolayı, GBAS sivil uçaklara yüksek navigasyon performansı sunan ileri bir navigasyon sistemi olarak tasarlanmıştır. GBAS'in bütün algoritmaları GPS konum belirleme çözümlerine dayanmaktadır. Bu çalışmada, alternatif bir uydu navigasyon sistemi olan GLONASS'ın gelecekte kullanılabilirliği dikkate alınmış olup performansı hesaplanmıştır. Bu anlamda, IST bir uygulama sahası olarak seçilmiştir. Seçilen uygulama alanı için performans hesaplamada iki yaklaşım kullanılmıştır; a) tam uydu sistemleri ile artan yükselti açısı değişimi, b) kötü senaryo olarak iki uydunun devre dışı bırakılması olarak hesaplamalarda kullanılmıştır. Bulgular GPS'in GLONASS'tan daha iyi GBAS şartlarını sağlayan yüksek bir performans sergilediğini göstermiştir. Öteyandan, alternatif bir uydu sistemi olan GLONASS'ın da belirlenen GBAS VPL değerlerine uyumlu olabileceği ve uçak hassas yaklaşma ve inişte IST için kullanılabileceği kanıtlanmıştır.
\end{abstract}




\section{Introduction}

The GBAS navigation system serves to civil aircraft users during their precision approach and landing within close range (i.e., up to $100 \mathrm{~km}$ ) to the airports (FAA 2005, Murphy and Imrich 2008). The system architecture is built on the GPS based navigation solutions performances; continuity, integrity, and accuracy (RTCA 1998, and 2000, and Sayim 2003). All these performances indicate that how well the navigation system provides the sufficient positioning solutions to the aircraft users with the use of the GPS constellation alone. However, the performance of an alternative constellation could be quantified and compared with GPS to assess navigation solutions between both constellations (GPS and GLONASS). Therefore, both constellations are used with same number of satellites, same time frame, in the same airport, and in entire analysis. It is also important to note that GBAS specifications are assumed identical for both constellations.

In analysis, two approaches have been used to determine the GBAS performances; 1 ) to quantify the availability in terms of elevation mask angle and 2) to deplete satellites in view from the constellations. For example, Sayim at al. 2015 and Wang at al. 2014 showed that the elevation mask could exceed the nominal 5 degree of mask due to various factors such as mountains/hills, building and high rises in near vicinity airports. This can be explained by the signal blockages due to obstacles in LOS (Line of Sight) to the satellite. For example, elevation masks limit the visibility of satellites in view directly and reduce the availability of system (Sayim at al. 2015). Thus, this duration of satellite rise or set time can be basically attributed to the GBAS unavailability. Therefore, the analysis is performed to predict the availability of the GBAS by varying the elevation masks in a certain range and then check if VPL performances supports aircraft landing under the prescribed system parameters (VPL<VAL) at the IST airport using both constellations.
In a constellation, a scheduled or an unscheduled satellite outage due to maintenance/maneuver is one of factor that must be considered in GBAS performance analysis (Pullen and Enge 2013). Therefore, all satellites in a constellation cannot always be guaranteed operational in the GBAS positioning solution. Thus, the GBAS operational availability is simulated based on the worst-case scenario of 2 satellite outages subset geometries through the VPL computations. In VPL computation, a Category I (CAT-1) aircraft approach and landing with B type airborne equipment is assumed. Protection Levels (VPLs) computed for every half second and then compared with the Vertical Alert Limit (VAL) of 10 meters. Exceeded VPL quantities to VAL are treated as unavailability of GBAS within duration of 24 hours.

For each constellation, a different quantity of GBAS availability has been computed as expected. It is investigated that the GBAS availability requirement severely affected by increased elevation masking for GPS and GLONASS. In the meantime, depleted constellations have produced significant results of impacted by the depletion. The geometry-critical satellites are determined. It is believed that using this information, ranked availability quantities, will be useful for obtaining satellite pair for high performance of GBAS availability. It is also recommended that a special care must be taken to geometry critical satellites in both constellations for performance improvement through maximization of system availability.

\section{GBAS Vertical Protection Levels}

The GBAS performance analysis is performed based on the GBAS requirements as defined in technical documents (FAA 2005, RTCA 1998, and 2000). A CAT-1 with $B$ type airborne equipment is assumed in analysis. The CAT-1 is defined (FAA 2005, RTCA 1998, and Reddy at al. 2012) as a precision approach and landing with a decision height not lower than $60 \mathrm{~m}$ and with either a visibility not less than $800 \mathrm{~m}$, or a runway visual range not less than $550 \mathrm{~m}$. In the CAT-1 requirements, the vertical accuracy (95\%) is 5 
$\mathrm{m}$, integrity is $4 \times 10^{-8} /$ approach, and availability is 0.999 within $10 \mathrm{~m}$ of Vertical Alert Limit (VAL) and 6 secs of time to alarm.

Navigation integrity of GBAS in vertical direction is ensured within the computation of the Protection Level (VPL) at the $10^{-8}$ probability of missed detection. Exceeded VPL quantities to VAL are stored for the duration of 24 hours. These events could happen if the number of satellites in view does not support the GBAS for initiation of intended aircraft approach and landing. Elevation mask is the limitation of satellite visibility at GBAS Ground Facility (GGF). In computation of VPLs, all Reference Receivers (RRs) measurements are assumed fault free (HO hypothesis). The VPL is given as (RTCA 1998, and 2000):

$$
\mathrm{VPL}_{\mathrm{H} 0}=5.85 \sqrt{\sum_{\mathrm{n}=1}^{\mathrm{N}} \mathbf{S}_{\mathrm{vertical,n}, \mathrm{n}}^{2}\left[\left(\sigma_{\mathrm{pr} \_ \text {gnd, }, \mathrm{n}}^{2} / 3\right)+\sigma_{\mathrm{pr} \_ \text {arr, } \mathrm{n}}^{2}+\sigma_{\mathrm{pr} \_ \text {res }, \mathrm{n}}^{2}\right]}
$$

$\mathbf{S}_{\text {vertical }}$ is the projection matrix third row and associates with the vertical positioning direction in the Least Square positioning solution as detailed are in GBAS documents (RTCA 1998, and 2000, and Sayim 2003). $n$ is the number of satellites in view at the time of position computation $(\mathrm{N} \geq 4), \mathrm{N}$ is the number of arbitrary satellite in view. Standard deviations of ground $\left(\sigma_{\text {pr_gnd }}\right)$, air $\left(\sigma_{\text {pr_air }}\right)$ and residual $\left(\sigma_{\text {pr_res }}\right.$ ) error are modelled in [1] accuracy designators. The Accuracy Designator (GAD and $A A D)$ describe the accuracy of different types of ground and airborne equipment (i.e., GPS receivers). The residual error models, ionosphere and troposphere, describe the spatial decorrelation.

\subsection{Ground Accuracy Designator (GAD).}

The accuracy allocation for ground error, using $C$ class ground equipment, is modelled by combining receiver noise, multipath, and the SIS residual error as follows (for three reference receivers, $M=3$ ) (RTCA 1998, and 2000): $\sigma_{\mathrm{pr}_{-} \text {gnd }}\left(\theta_{\mathrm{i}}\right) \leq\left\{\begin{array}{cc}\sqrt{\left(0.15+0.84 \mathrm{e}^{-\theta_{\mathrm{t}} / 15.5}\right)^{2} / 3+0.0016+\left(0.01 / \sin \theta_{\mathrm{i}}\right)^{2}} & \theta_{\mathrm{i}}>35 \\ \sqrt{(0.24)^{2} / 3+0.0016+\left(0.01 / \sin \theta_{\mathrm{i}}\right)^{2}} & \theta_{\mathrm{i}} \leq 35\end{array}\right.$

Where, $\theta_{i}$ is elevation angle of the satellite (degrees) for the $\mathrm{i}^{\text {th }}$ ranging source.

\subsection{Airborne Accuracy Designator (AAD).}

The AAD models the error due to wide band noise, interference and error due to airframe multipath. The achievable receiver technology performance for aviation (B-Class equipment) is:

$$
\sigma_{\text {pr_air }}\left(\theta_{\mathrm{i}}\right) \leq 0.0741+0.18 \mathrm{e}^{-\theta_{\mathrm{i}} / 27.7}
$$

\subsection{Residual Error Model.}

The accuracy models, residual effects due to ionospheric and tropospheric spatial decorrelation, are combined into a single term as (RTCA 1998, and 2000):

$\sigma_{\mathrm{pr} \_ \text {res }}=\sqrt{\sigma_{\mathrm{pr} \_ \text {tropo }}^{2}+\sigma_{\mathrm{pr}_{-} \text {iono }}^{2}}$

Where the $\sigma_{\text {pr_tropo }}$ is the Tropospheric Uncertainty due to spatial decorrelation and is modeled as (RTCA 1998, and 2000):;

$$
\sigma_{\text {pr }- \text { trop }}=10^{-6} \sigma_{\mathrm{R}} \mathrm{h}_{0} / \sqrt{0.002+\sin ^{2}\left(\theta_{\mathrm{i}}\right)}\left(1-\mathrm{e}^{-\Delta_{\mathrm{h}} / \mathrm{h}_{0}}\right)
$$

where,

$\sigma_{R}$ is refractivity uncertainty (10 unit-less).

$\mathrm{h}_{0}$ is tropospheric scale height (7600 meters).

$\Delta_{\mathrm{h}}$ is aircraft distance above reference station (3000 meters).

The $\sigma_{\text {pr_iono }}$ is the Ionospheric Uncertainty due to spatial decorrelation and it is modeled as (RTCA 1998, and 2000);

$$
\sigma_{\text {pr_iono }}=\frac{\sigma_{\text {vert_iono_grad }}\left(\mathrm{x}_{\text {air }}+2 \tau_{\text {air }} \nu_{\text {air }}\right)}{1-\left(\mathrm{R}_{\mathrm{e}} \cos \left(\theta_{\mathrm{i}}\right) /\left(\mathrm{R}_{\mathrm{e}}+\mathrm{h}_{\mathrm{I}}\right)\right)^{2}}
$$

where, 
$\tau_{\text {air }}$ is the airborne carrier-smoothing time constant (100 sec),

$v_{\text {air }}$ is the horizontal user velocity ( $\left.70 \mathrm{~m} / \mathrm{sec}\right)$,

$\sigma_{\text {vert_iono_grad }}$ is the ionospheric delay change (as a function of ionospheric pierce-points separation between reference receiver and user, $\sim 2 \mathrm{~mm} / \mathrm{km}$ ), $\mathrm{X}_{\text {air }}$ is the user-reference separation,

$\mathrm{R}_{\mathrm{e}}$ is the approximate radius of Earth's ellipsoid $(6378.1363 \mathrm{~km})$,

$\mathrm{h}_{\mathrm{I}}$ is the height of the maximum electron density of the ionosphere ( 350 km).

\section{Results and Discussions.}

The GBAS availability is quantified as the total duration of time in which the VPL is less than VAL within simulation time. Therefore, it is performed through computation of VPL via MATLAB programing. VPL indicates position error upper bounds at the aircraft for a precision approach and landing under a fault free hypothesis ( $\mathrm{HO})$. Two approaches have been tested in producing the VPL computation and results: 1- varying elevation mask (i.e., for limiting the visibility of satellite geometries in space) and 2- depleting the constellations as worst-case scenario in geometric combinations of subsets in satellites in view.

In Figure 1, VPL quantities are plotted over 24 hours. Each curve represents one constellation as labeled on the figure. These curves are obtained at nominal 5-degree elevation mask with use of full constellations at IST. In comparison of variation of VPLs within nominal conditions, GPS has better performance over GLONASS. Specifically, from $11^{\text {th }}$ to $16^{\text {th }}$ hours, a large separation on VPLs between both constellations has been experienced.

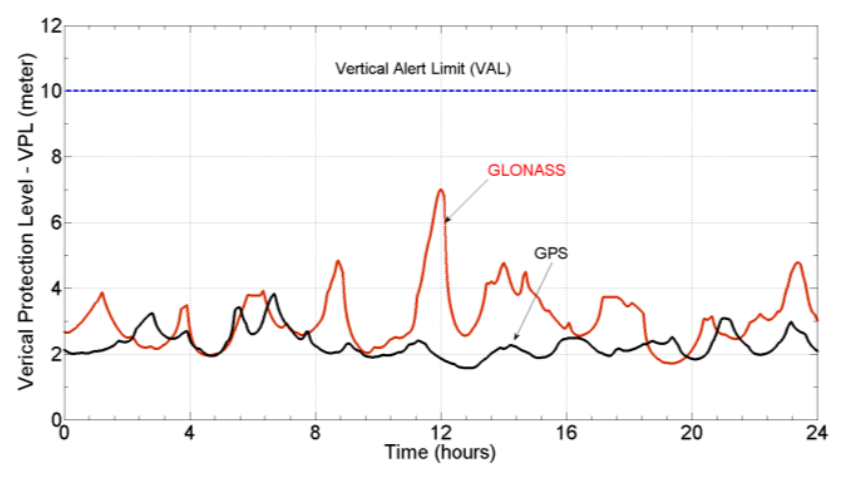

Figure 1. Vertical Protection Levels (VPLs) at 5-degree nominal elevation mask for GPS and GLONASS at IST

In Figure 2, all satellite passes are plotted over 24 hours for both constellations. Horizontal axis is azimuth and vertical is elevation angle. As labeled in this figure, nominal 5-degree elevation mask is selected to limit visibility of the satellite passes as indicated in GBAS specifications. It is also simply shown that the geometric coverage of each constellation in sky.

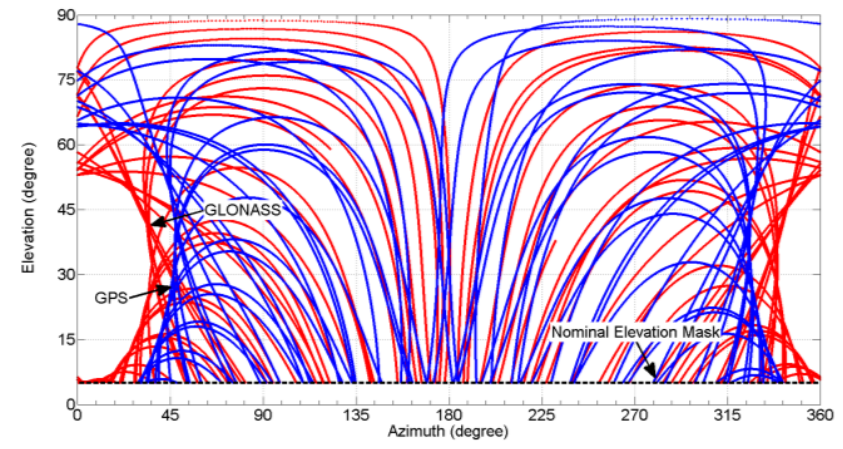

Figure 2. Satellites passes in terms of Azimuth-Elevation for GPS and GLONASS

The error models are described in GBAS standard in terms of accuracy expectations from ground and airborne equipment. In analysis, specificationsvalues are used directly from the GBAS documents (FFA 2005, RTCA 1998, and 2000). However, the satellite elevation masking is varied from zero to twenty degrees. A simulation was executed with the use of both constellations to perform availability analysis for Istanbul Ataturk Airport (IST). The details of the data used in simulation are:

- Constellation: GPS and GLONASS Nominal 24satellites.

- GBAS Site Location: Istanbul Ataturk Airport (ISG) (Lat: $40.982555^{\circ}$, Lon: $28.820829^{\circ}$ )

- Simulation Duration: 24 hours

- Time interval: $0.5 \mathrm{sec}(2 \mathrm{~Hz})$

- Satellite Outage Conditions: 1-complete 24satellite constellation and 2- depleted constellation with two satellite outages

GBAS Vertical Protection Levels are computed every half second and compared with Vertical Alert Limits. The geometries in which the VPL is greater than VAL 
are determined as GBAS unavailability. These cases do not support GBAS for the aircraft approaches and landing. When the availability condition is satisfied, the GBAS Signal in Space (GBAS SIS) is rated safe for aircraft approach and landing. In Figure 1, details of the computed VPLs are given. For nominal values in specification including elevation mask (5-degree), the VPLs are not exceed to VAL (i.e., no threat of GBAS availability) when full constellation is used. However, undoubtedly, increased value of elevation mask produced some geometries that do not necessarily support the GBAS availability as shown in figure 3.

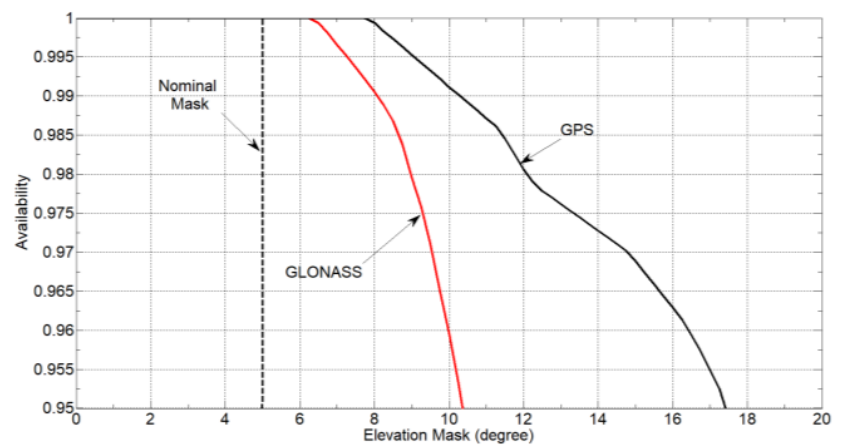

Figure 3. Availability in terms of elevation mask variation at IST for GPS and GLONASS

Elevation mask is finely spaced from 0 to 20 degrees with half degree interval as shown in horizontal axis in Figure 3. Vertical axis represents the computed availability of GBAS at each time interval over 24 hours. Dashed vertical line is the nominal value of elevation mask of 5-degree as defined GBAS specs. In this figure, the availability performances for both constellations are graphed. GLONASS curve exceeds the required availability at lower elevation mask values whereas the GPS exceeds the required availability at high elevation mask values. In this way, the GBAS VPL performances are compared between two constellations. The GPS has superior performance over the GLONASS.

The worst-case satellite outages (depleted constellation, 22 satellite subsets out of 24) may not necessarily guarantee the required availability GBAS at the level of $99.9 \%$. Additionally, the availability is decreased if elevation mask is above the nominal value of 5-degree. In Figure 4, multiple VPL curves
(276 cases of satellite subsets) are plotted for duration of 24 hours for GPS. Each curve represents one pair of satellite outage (depleted constellation, 22 satellite subsets out of 24). A 10-meter horizontal dashed line indicates the required VAL value for CAT-1. It is observed that the VPLs are exceeded VAL for many subsets of 22 satellites within 24 . In Figure 5, computed VPL values of depleted constellation of GLONASS are plotted for duration of 24 hours. It is simply observed that much more exceedances of VAL are in this figure comparing with Figure 4. This indicates a lower availability for using the GLONASS.

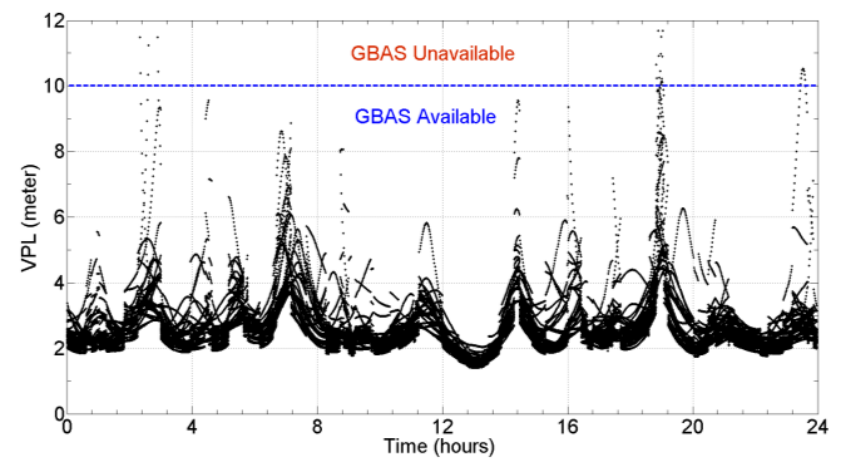

Figure 4. 24 hours VPLs variations in case two satellites outages for GPS at five-degree elevation mask fixed.

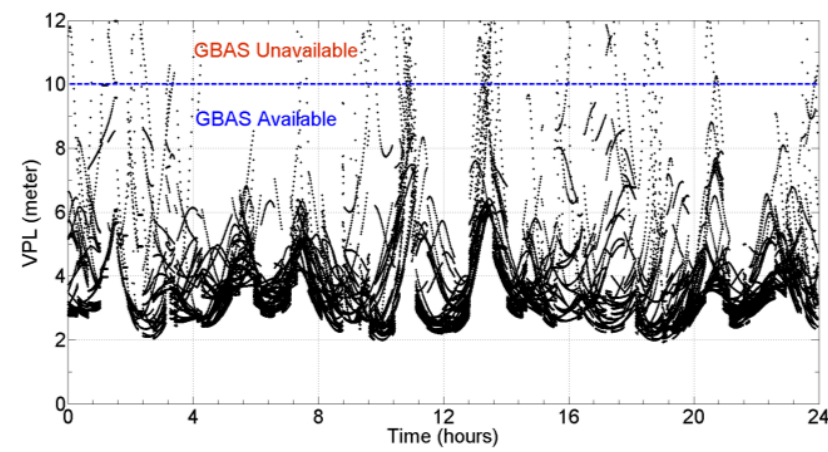

Figure 5. 24 hours VPLs variations in case two satellites outages for GLONASS at five-degree elevation mask fixed.

In Figure 6, the availability of GBAS for both constellations are plotted in terms of satellite outages. Horizontal axis shows cases (each satellite pairs) of satellite outage subsets. Two main observations; 1- indicating that each outage pair has different impact on the availability of GBAS, 2- the relative availability performance between two constellations is favor of GPS. 


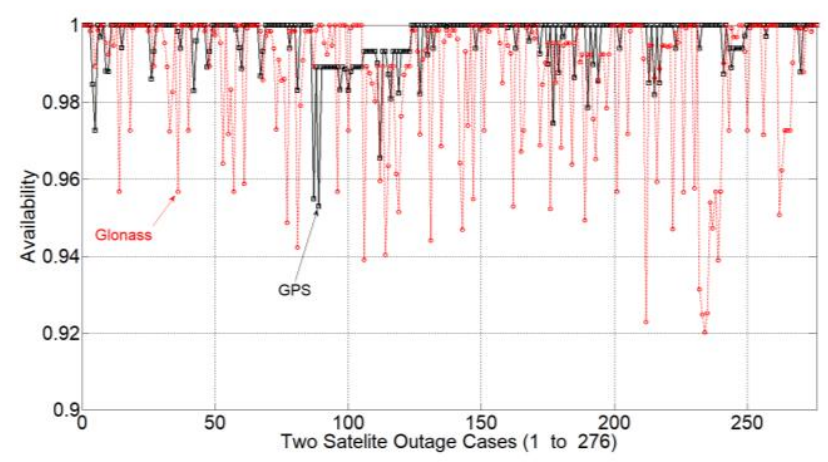

Figure 6. Availability in terms of satellite outages for GPS and GLONASS

\section{Conclusions}

In this paper, the usability of GLONASS under the current GBAS requirements is analyzed at the Istanbul Ataturk Airport - IST. GPS and GLONASS performances, in this respect, have been quantified and compared. We are noting that the GLONASS related accuracy designators such as $A A D / G A D$ are not defined yet. In analysis, the GBAS specifications were used only as a basis for GLONASS performance computations. Therefore, the results, obtained in the paper, give a conceptual idea about the geometric performance of GLONASS rather than its full performance. In analysis, two strategies have been applied in quantification process of GBAS performance. Following specific conclusions can be drawn from this work.

- $\quad$ Performances of both constellations (GPS and GLONASS) have complied with the GBAS specifications at 5-degree elevation mask in IST. In other word, with the use of full constellations (24 satellites), the availability of GBAS was computed greater than 0.999 for given site where this is consistent with the specification (FFA 2005, RTCA 1998, and 2000). However, the GPS has greater performance over GLONASS.

- In general, in case of use of two satellite outages (22 out of 24 satellites at any instant time) with 5-degree mask, the availability of GBAS has been well below the requirements for both constellations in many subsets of satellite outages. Although some satellite outages (Figure 4) results a considerable degradation on the GBAS availability, a significant subsets of satellite pairs do not impact on the availability. From this outcome, we can identify the geometry-critical satellites or satellite pairs.

\section{Acknowledgment}

It is also noted that the views expressed in this paper belong to the authors alone and do not necessarily represent the position of any other organization or person.

\section{References}

FAA Specification (2005) Category I Local Area Augmentation System Ground Facility. FAA, Washington, D.C., FAA-E-AJW44-2937A, October 21

Murphy T., and Imrich T., (2008) "Implementation and Operational Use of Ground-Based Augmentation Systems (GBASs) - A Component of the Future Air Traffic Management System," Proceedings of the IEEE, Volume 96, Number 12, pp 1936- 1957

Pullen, S. and Enge, P. (2013), "Using Outage History to Exclude High-Risk Satellites from GBAS Corrections." Journal of Institute of Navigation, 60: 41-51. doi:10.1002/navi.20

Reddy A. S., Jhansi B., and Sarma A. D., (2012) "Analysis of Future LAAS 'Availability' at Hyderabad Station for Precision Approach of Aircraft", India Conference (INDICON), 2012 Annual IEEE, Kochi, Kerala, India, Date 7-9, December 2012

RTCA (SC-159/WG-4), (1998) Minimum Aviation System Performance Standards for the Local Area Augmentation System (LAAS)," RTCA/DO-245, RTCA Inc., Washington DC, 28 September 1998.

RTCA (SC-159/WG-4), (2000) “Minimum Operational Performance Standards for GPS Local Area Augmentation System Airborne Equipment," RTCA DO-253, RTCA Inc., Washington, D.C., 11 January

Sayim I., Kavzoglu T., and Sahin, E., (2015) “GBAS Availability Analysis for the Trabzon Airport Using True Terrain Masking Data," 7nd International Conference on Recent Advances in Space Technologies (RAST 2015), June 16-19, 2015, Istanbul, Turkey.

Sayim, I., (2003) "Ranging Error Overbounds for Navigation Integrity of Local Area Augmented GPS," Ph.D. Dissertation, Illinois Institute of Technology, Chicago, IL

Wang Z., Macabiau C., Zhang J., and Escher A. C. (2014) "Prediction and analysis of GBAS integrity monitoring availability at LinZhi airport", GPS Solution, 18, 17-40 